NASA Technical Memorandum 86801

NASA-TM-86801 19860016867

\title{
Decoupling Control Synthesis for an Oblique-Wing Aircraft
}

Gurbux S. Alag, Robert W. Kempel, and Joseph W. Pahle

HanAMY RaPY

. ? $\because 30$

LANGLEY FESEARCH CENTER

LIERARY, NASA

HA:.PTOEN 2 VIRGINIA

\section{N/SA}

National Aeronautics and

Space Admınıstratıon 


\section{Decoupling Control Synthesis for an Oblique-Wing Aircraft}

Gurbux S Alag

Western Michıgan University, Kalamazoo, Michıgan

Robert $W$ Kempel and Joseph W Pahle

Ames Research Center, Dryden Flight Research Facility, Edwards, California

\section{N/Sก}

National Aeronautics and

Space Admınıstration

Ames Research Center

Dryden Flight Research Facility

Edwards, Calıfornı 93523 


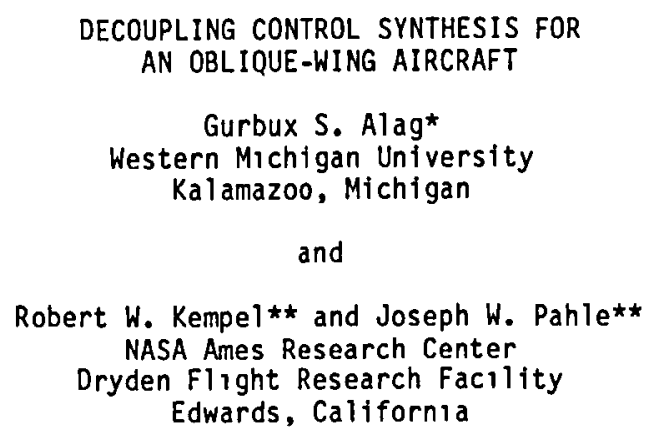

\section{Abstract}

Interest in oblique-wing arrcraft has surfaced periodically since the 1940 's. This concept offers some substantial aerodynamic performance advantages but also has significant aerodynamic and inertial cross-coupling between the aircraft longitudinal and lateral-directional axes. This paper presents a technique for synthesizing a decoupling controller while providing the desired stability augnentation.

The proposed synthesis procedure uses the concept of a real model-following control system. Feedforward gains are selected on the assumption that perfect model-following conditions are satisfied. The feedback gains are obtained by using eigensystem assignment, and the aircraft is stabilized by using partial state feedback. The effectiveness of the control laws developed in achleving the desired decoupling is 1 llustrated by application to linearized equations of motion of an oblique-wing aircraft for a given flight condition.

\section{Nomenclature}

\section{$A, B, C \quad$ system matrices}

d eigenvector of components, unspecified

e error

I identity matrix

j $\sqrt{-1}$

K feedback gain

$L, M \quad$ matrices of appropriate dimension

OWRA Oblique-wing research aircraft

p roll rate, $\mathrm{deg} / \mathrm{sec}$

q pitch rate, $\mathrm{deg} / \mathrm{sec}$

RMF real model-following

$r \quad$ yaw rate, $\mathrm{deg} / \mathrm{sec}$

\footnotetext{
*Associate Professor, Electrical Engineering Department.
}

**Aerospace Engıneer.
$\mathbf{S}$

U

y

Z

B

$\delta$

$\theta$

$\lambda$

$\phi$

$(\ldots)^{R_{1}}$

Subscripts

aL

left afleron

$\mathrm{aR}$

right aileron

hl

left horizontal

$\mathrm{hR}$

i

m

$p$

$\mathbf{R}$

X

right horizontal

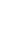

th value

model

plant (aircraft)

set of real numbers

input vector

state vector

Superscripts

number of outputs 


\section{Introduction}

The advantages of an oblique wing were first noted in the 1940's. However, only recently has the interest, technology, and mission of an oblique-wing design evolved into a full-scale flight research program. The NASA Ames Research Center and the U.S. Navy are developing an oblique-wing research aircraft (OWRA). Gregoryl has outlined a number of potential advantages and disadvantages of this type of airplane. Theoretical and wind-tunnel studies have shown that a variable skew oblique wing offers a substantial aerodynamic performance advantage for aircraft missions that require both high efficiency in subsonic flight and supersonic dash or cruise. The most obvious disadvantage of the oblique-wing concept is the asymmetry associated with wing-skew angle. This asymmetry results in significant aerodynamic and inertial cross-coupling between the aircraft longitudinal and lateral-directional axes. Current typical design procedures synthesize aircraft controllers based on 2- or at most 3-degree-of-freedom solutions. However, the OWRA stabilization and decoupling must consider at least 5 degrees of freedom simultaneously.

The basis for OWRA will be NASA's F-8 digital fly-by-wire alrcraft. This aircraft will be modified by the removal of the current high wing and installation of a wing pivot and a composite wing. A major part of the OWRA program will be the synthesis of a control system that will provide acceptable stabilization and decoupling across the Mach, angle-of-attack, and wing-skew envelope. The aircraft thus offers an opportunity to apply modern control theory techniques to the solution of problems associated with OWRA.

Model-following has been a popular method for the design of multivariable control systems over the last two decades. In this method, the desired behavior of the plant is provided by an ideal model, and the problem is one of designing a suitable controller for the plant so that its response follows that of the model.

Yore 2 indicated the use of this method for simultaneous stability augmentation and mode decoupling. His synthesis procedure consisted of constructing an ideal model, designing feedback gains by quadratic optimization, and designing feedforward gains. A disadvantage of this method is that selection of feedback gain is an iterative and time-consuming process. The determination of this gain becomes a more complex problem when all states are not avallable and therefore output feedback 15 used.

Another technique for decoupled flight control design is the eigenstructure assignment. 3 In this technique, the performance specifications can be interpreted in terms of the eigenvalues and elgenvectors of the closed-loop system. Broussard and Berry 4 have established the equivalence of this technique to the design using model-following systems.

In this paper, the development of control laws for OWRA by integration of the two above-mentioned techniques is demonstrated. The resuits show the effectiveness of the controller in obtaining the decoupled response for a given flight condition and wing skew.

\section{Problem Definition}

The concept of model-following is useful when an ideal set of plant equations of motion can be specified. The ideal objective of model-following flight control is to force the aircraft to respond as the model would to a given pilot command. It is often desirable to simulate the model dynamics in the flight computer and to generate the alrcraft control signal using the aircraft outputs, the pilot input commands, and the model states. This situation is sometimes referred to as the pilot flying the computer, whlle the computer is flying the aircraft.

More precisely, the model-following problem can be stated as follows. The linearized dynamics are given as

$$
\begin{aligned}
& \dot{x}_{p}=A_{p} x_{p}+B_{p} u_{p} \\
& y_{p}=C x_{p}
\end{aligned}
$$

where $x_{p} \in R^{n}, u_{p} \in R^{m}$, and $y_{p} \in R^{l}$, and $A_{p}, B_{p}$, and $C$ are matrices of appropriate dimensions. The control up must be determined such that the plant output $y_{p}$ approximates, reasonably well, some model output vector $y_{m}$ defined by the equations:

$$
\begin{aligned}
& \dot{x}_{m}=A_{m} x_{m}+B m u_{m} \\
& y_{m}=C x_{m}
\end{aligned}
$$

where $x_{m} \varepsilon R^{n}, u_{m} \varepsilon R^{m}$, and $y_{m} \in R^{l}$, and $A_{m}, B_{m}$, and $C$ are matrices of appropriate dimensions.

For OWRA, the state, Input, and output vectors are given by

$X=\left[\begin{array}{l}v \\ \alpha \\ B \\ \phi \\ \theta \\ p \\ q \\ r\end{array}\right]$

$u=\left[\begin{array}{l}\delta_{\mathrm{hL}} \\ \delta_{\mathrm{hR}} \\ \delta_{\mathrm{aL}} \\ \delta_{\mathrm{aR}} \\ \delta_{\mathrm{R}}\end{array}\right]$

$y=\left[\begin{array}{l}p \\ q \\ r \\ \phi \\ \alpha \\ \beta\end{array}\right]$ velocity, $\mathrm{m} / \mathrm{sec}$ angle of attack, deg sideslip angle, deg bank angle, deg pitch angle, deg roll rate, deg/sec pitch rate, deg/sec yaw rate, deg/sec

left horizontal tail deflection, deg right horizontal tall deflection, deg left aileron deflection, deg right alleron deflection, deg rudder deflection, deg

roll rate, deg/sec pitch rate, deg/sec yaw rate, $\mathrm{deg} / \mathrm{sec}$ bank angle, deg angle of attack, deg sideslip angle, deg 
The desired model of the alrcraft, defined by matrices $A_{m}$ and $B_{m}$ as well as the alrcraft matrices $A_{p}$ and $B_{p}$ are given in Table 1. The aircraft matrices correspond to a flight condition of 0.8 Mach number and an altitude of $6096 \mathrm{~m}$ at $45^{\circ}$ wing skew. The model used in this study is a modification of the zero-wing-skew configuration at the same flight condition. $A_{m}$ and $B_{m}$ elements are modified to increase damping and to eliminate zero-wing-skew coupling terms. This model is preliminary and may not represent 1 deal dynamics but does incorporate the desired aircraft decoupling.

\section{Model-Following Control System}

There are two configurations of modelfollowing, one is implicit model-following, and the other is real model-following (RMF). In implicit model-following, the model is not part of the system. In RPIF, however, the model is part of the system as control law requires the states of the model. The technique of RMF has been shown to be amenable to the solution of many alrcraft control problems.

Frzberger ${ }^{5}$ established conditions for perfect model-following that enable an ideal match of the dynamics of the compensated plant with those of the model. However, the conditions for perfect model-following are never attainable in the real world. An asymptotic RMF control law was derived by Chan 6 for the class of plants and models whose output vectors are identically their state vectors. Chan showed that, even if the conditions for perfect model-following are not satisfied, use of perfect model-following gains can yield a control capable of keeping error between the model and plant to a "small" region of state space. Chan chose $u_{p}$ as

$$
u_{p}=u_{1}+u_{2}
$$

where

$$
\begin{aligned}
u_{1} & =k_{e} \\
u_{2} & =B_{p}^{\dagger}\left(A_{m}-A_{p}\right) x_{m}+B_{p}^{\dagger} B_{m} u_{m} \\
& =k_{x m} x_{m}+k_{u m} u_{m}
\end{aligned}
$$

and $B_{p}^{\dagger}$ is the pseudo-inverse of $B_{p}$, and $K_{x m}$ and $K_{\text {um }}$ are the feedforward gains using model states and command input. Also,

$$
p=x_{m}-x_{p}
$$

The control $u_{p}$ will ensure perfect modelfollowing, if it is possible. If perfect modelfollowing is not possible, the error setting rates would depend on ergenvalues of the closedloop system and can thus be controlled in RMF. Also, if only partial state feedback is possible in the plant, perfect real model-following is still possible.

For OWRA, because partial state feedback is to be used, the feedback gain $K$ must be selected to ensure stability of the closed-loop alreraft and placement of its closed-loop ergenvalues at the desired location in the s-plane. The method of elgenstructure assignment will be used to select the gain $k$. This enables the desired eigenvectors and eigenvalues to be selected to ensure satisfactory tranisient response of the aircraft.

\section{Ergensystem Synthesis}

Two widely used synthesis techniques of modern control theory are the Iinear quadratic regulator design and the modal control theory involving pole placement or eigenvalue-eigenvector assignment.7 One of the purposes of feedback control of aircraft is to improve or enhance the flying qualities of an alrcraft. The difficulty in incorporating specifications such as damping, natural frequency, and decoupling within a quadratic performance index makes the eigensystem synthesis procedure a promising design alternative. The performance specifications can be interpreted in terms of desired closed-loop eigenvalues and eigenvectors. Moore ${ }^{8}$ and others have shown how feedback can be used to place closed-loop eigenvalue and shape closed-loop eigenvectors. Cunningham ${ }^{9}$, and Andry, Shapiro, and Chung, 10 and Sobel and Shapiroll have successfully demonstrated the use of eigenstructure assignment procedure for aircraft control system design.

The handling qualities data base may be used to obtain desired pole locations directly. The additional design objective of obtaining augmented dynamics similar to those obtained in flight leads to specifications on eigenvectors or desired mode shapes. For example, pitch attitude must be dominant for the short-period mode, and speed must be dominant for the phugoid mode.

Detarled discussions on eigenspace may be found in Ref. 11. However, some basic results for controllable and observable systems are summarized in the following discussion.12

\section{Consider the system}

$$
\begin{aligned}
& \dot{x}=A x+B u \\
& y=C x
\end{aligned}
$$

where $x \in R n, u \in R^{m}$, and $y \varepsilon R^{2}$, and $A, B$, and $C$ are matrices of appropriate dimensions. If the system is controllable and observable, and the matrices $B$ and $C$ are full rank, the following results hold

1. The positions of maximum $(m, l)$ closed-loop eigenvalues can be assigned arbitrarily with the stipulation that if $\lambda_{1}$ is a complex closed-loop eigenvalue, its complex conjugate $\lambda_{1}^{\star}$ must also be a closed-loop eigenvalue.

2. The shape of maximum $(m, \mathbb{C})$ elgenvectors can be altered. If the shape of a complex eigenvector $v_{1}$ is altered, its complex conjugate $v_{1}^{*}$ must be altered in the same way.

3. For each eigenvector whose shape is altered, minimum $(m, r)$ elgenvector elements can be chosen arbitrarily. 
4. Attainable ergenvectors must lie in the subspace spanned by the columns of $\left(\lambda_{1} I-A\right)^{-1} B$ of dimension $\mathrm{m}$ that is the number of independent control variables. A desired eigenvector $v_{1}^{d} w_{111}$, in general, not reside in the prescribed subspace and cannot be achieved. The achievable eigenvector $v_{1}^{a}$ is obtained by orthogonal projection of $v_{1}^{d}$ onto the subspace spanned by $\left(\lambda_{1} I-A\right)^{-1} B$. It will generally be true that only a few of the components in $v_{1}$ are actually specified. The remainder can be arbitrary. To account for this, $v_{1}$ is reordered and partitioned as follows

$$
\left(v_{1}\right)^{R_{1}}=\left(\frac{v_{1}^{\star}}{d_{1}}\right)
$$

where

$$
\begin{aligned}
& v_{1}^{*}=\text { the specified subvector } \\
& d_{1}=\text { the vector of unspecified components }
\end{aligned}
$$

$(\text {. . })^{R_{1}}=$ the reordering operation

If we let

$$
\left(\frac{v_{1}^{0}}{d_{1}}\right)=\left[\left(\lambda_{1} I-A\right)^{-1} B\right]^{R_{1}} Z_{1}=\left(\frac{L}{M}\right) z_{1}
$$

then, as shown in Ref. 13, $z_{1}$ may be selected to best approximate $v_{1}^{*}$ with $v_{1}^{0}$. By the method of orthogonal projections, $z_{1}$ is obtained

$$
z_{1}=\left(L^{\prime} L\right)^{-1} L^{\prime} v_{1}^{*}
$$

As shown by Moore ${ }^{8}$, the feedback gain $K$ is given by

$$
K=\left(w_{1} w_{2} \ldots w_{n}\right)\left(v_{1} v_{2} \ldots v_{n}\right)^{-1}
$$

where $w_{1}$ is obtained from the relation

$$
\begin{gathered}
\left(\lambda_{1} I-A\right) v_{1}=B w_{1} \\
\text { Results }
\end{gathered}
$$

To illustrate the degree of coupling in the open-loop system and decoupling in the closedloop system, a one-degree control command was input for $2 \mathrm{sec}$ as shown in Fig. 1. This command input was either elevator or aileron and was reduced to zero after $2 \mathrm{sec}$. Figures $2(\mathrm{a})$ to $2(\mathrm{c})$ 1 llustrate the open-loop system response to an elevator command input for pitch rate, yaw rate, and bank angle, respectively. Significant yaw rate and bank angle are generated as a result of the pitch command, and of particular interest is the very large change in bank angle illustrating the significant cross-coupling.

Table 2 shows the desired eigenvector assiynment specitication, open- and closed-loop eigen- values and desired eigenvalues, the feedback gain matrix $K$, and the feedforward gain matrices $\mathrm{K}_{\mathrm{xm}}$ and $\mathrm{K}_{\mathrm{um}}$.

Figures $3(\mathrm{a})$ to $3(\mathrm{c})$ and 4 illustrate the closed-loop system response to the same elevator command input. The pitch rate in Fig. 3(a) is attenuated as compared with the open-loop response. However, the system is very closely following the desired model response as illustrated in Fig. 4. The yaw rate and bank angle are virtually nonexistent as 11 lustrated in Figs. 3(b) and $3(\mathrm{c})$, thus achieving the desired decoupling.

Figures $5(\mathrm{a})$ to $5(\mathrm{c})$ illustrate the open-loop system response to a one-degree al leron command input. Pitch and yaw angular rate and bank angle are again shown. The relative pitch coupling is not as severe for the alleron command case as the roll coupling is for the elevator command, however, coupling is still present.

Figures $6(a)$ to $6(c), 7(a)$, and $7(b) 111 u 5$ trate the closed-loop system response to the same aileron command. Pitch rate is virtually nonexistent, and the desired yaw rate and bank angle are achieved, giving the desired decoupling.

\section{Conclusions}

A method is presented to obtain a decoupled control for a highly coupled asymmetric aircraft. The method utilizes a real model-following control law in which gains for perfect model-following are used even when the conditions for perfect modelfollowing are not satisfied. The feedback gain, using output feedback, is computed by using eigenstructure assignment. The results indicate that the method does obtain the decoupliny incorporated in the ideal model for the flight condition considered.

Future investigations will be conducted to evaluate the control alyorithm under nonlinear 6 -degree-of-freedom flight conditions. These investigations will consider such factors as nonlinear aerodynamic data, control system surface rate and position constraints, and system hysteresis.

\section{References}

1Gregory, T., "Oblique Wing Ready for Research Aircraft," Aerospace America, June 1985, pp. 78-81.

2Yore, E., "Optimal Decoupling Control," 9th Joint Automatic Control Conference of the American Automatic Control Council, New York, 1968, pp. 327-336.

${ }^{3}$ Srinathkumar, S., "Modal Control Theory and Application to Aircraft Lateral Handling Qualities Design," NASA TP-1234, 1978.

4Broussard, J.R., and Berry, P.W., "The Relationship Between Implicit Model Following and Eigenvalue Elgenvector Placement, "Proceedings IEEE Conference on Decision and Control,

Oct. 1979, pp. 38-42. 
5Erzberger, H., "On the Use of Algebraic Methods in the Analysis and Design of Model-Following Control Systems," NASA TN D-4663, 1968.

${ }^{6}$ Chan, Y.T., "Perfect Model Following with a Real Mode1," 14th Joint Automatic Control Conference of the American Automatic Control Counci 1, Columbus, Oh10, Paper 10-5, 1973, pp. 287-293.

7Alag, G.S., and Duke, E.L., "Development of Control Laws for a Flight Test Maneuver Autopilot for an F-1b Aircraft," NASA TM-86736, 1985.

8Moore, B.C., "On the Flexibility offered by Full State Feedback in Multivariable Systems Beyond Closed Loop Eigenvalue Assignment," IEEE Trans. Auto. Control, Vol. 21, 0ct. 1976, pp. 689-692.

${ }^{9}$ Cunningham, T.B., "E1genspace Selection Procedures for Close Loop Response Shaping with
Modal Control," Proceedings of the IEEE Conference on Decision and Control, Dec. 1980, pp.178-186.

10 Andry, A.N., Shapıro, E.Y., and Chung, J.C., "On Eigenstructure Assignment for Linear Systems," IEEE Transactions Aerospace and Electronic Systems, Sept. 1983, pp. 711-729.

11Sobel, K.M., and Shapiro, E.Y., "Application of Eigensystem Assignment to Lateral Translation and Yaw Pointing Flight Control," 23rd IEEE Conference on Decision and Control, Las Vegas, Nev., Dec. 1984, pp. 1423-1428.

12Liebst, B.S., Garrard, W.L., and Adams, W.M., "Eigenspace Design of an Active Flutter Suppression System," AIAA Paper 84-1867, Aug. 1984.

13Harvey, C.A., Stein, G., and Doyle, J.C., "Opt1mal Linear Control Characterization of MultiInput Systems," ONR-CR-215-238-2, TR-2, 1977.

TABLE 1. - AIRCRAFT AND MODEL MATRICES

\begin{tabular}{|c|c|c|c|c|c|c|c|c|}
\hline \multicolumn{9}{|c|}{ Plant (aırcraft) matrices } \\
\hline$A_{p}=$ & {$\left[\begin{array}{r}0.0094 \\
-0.0001 \\
0.0000 \\
0.0000 \\
0.0000 \\
0.0000 \\
-0.0002 \\
0.0000\end{array}\right.$} & $\begin{array}{r}22.0707 \\
-0.7826 \\
-0.0592 \\
0.0000 \\
0.0000 \\
33.1432 \\
-8.6816 \\
-1.0092\end{array}$ & $\begin{array}{r}10.5479 \\
0.0958 \\
-0.2908 \\
0.0000 \\
0.0000 \\
-53.6933 \\
0.7975 \\
10.7521\end{array}$ & $\begin{array}{r}-0.1341 \\
0.0000 \\
0.0387 \\
0.0000 \\
0.0000 \\
0.0000 \\
0.0000 \\
0.0000\end{array}$ & $\begin{array}{r}-32.1127 \\
0.0000 \\
-0.0002 \\
0.0000 \\
0.0000 \\
0.0000 \\
0.0000 \\
0.0000\end{array}$ & $\begin{array}{r}0.0057 \\
0.0030 \\
0.0259 \\
1.0000 \\
0.0000 \\
-3.1250 \\
0.1679 \\
-0.0213\end{array}$ & $\begin{array}{r}-0.0005 \\
0.9926 \\
0.0001 \\
0.0000 \\
1.0000 \\
2.0552 \\
-1.0352 \\
0.0080\end{array}$ & $\left.\begin{array}{r}-0.0265 \\
-0.0003 \\
-0.9920 \\
0.0247 \\
0.0000 \\
1.7210 \\
0.1810 \\
-0.7129\end{array}\right]$ \\
\hline$B_{p}=$ & {$\left[\begin{array}{r}0.0844 \\
-0.0974 \\
-0.0166 \\
0.0000 \\
0.0000 \\
12.9804 \\
-9.4073 \\
1.9854\end{array}\right.$} & $\begin{array}{r}-0.0309 \\
-0.0974 \\
0.0166 \\
0.0000 \\
0.0000 \\
-22.2654 \\
-10.8655 \\
-2.2579\end{array}$ & $\begin{array}{r}-0.2210 \\
-0.0198 \\
0.0008 \\
0.0000 \\
0.0000 \\
15.8467 \\
-1.2311 \\
0.5262\end{array}$ & $\begin{array}{r}-1.2572 \\
-0.0302 \\
-0.0005 \\
0.0000 \\
0.0000 \\
-11.8422 \\
0.8797 \\
-0.3276\end{array}$ & $\begin{array}{r}3.6598 \\
0.0000 \\
0.0647 \\
0.0000 \\
0.0000 \\
13.2774 \\
0.5694 \\
-6.2499\end{array}$ & & & \\
\hline \multicolumn{9}{|c|}{ Model matrices } \\
\hline$A_{m}=$ & {$\left[\begin{array}{r}-0.0077 \\
-0.0001 \\
0.0000 \\
0.0000 \\
0.0000 \\
0.0000 \\
0.0001 \\
0.0000\end{array}\right.$} & $\begin{array}{r}23.5966 \\
-1.1062 \\
0.0000 \\
0.0000 \\
0.0000 \\
0.0000 \\
-12.1514 \\
0.0000\end{array}$ & $\begin{array}{r}0.0000 \\
0.0000 \\
-0.6000 \\
0.0000 \\
0.0000 \\
-44.3777 \\
0.0000 \\
12.1943\end{array}$ & $\begin{array}{l}0.0000 \\
0.0000 \\
0.0387 \\
0.0000 \\
0.0000 \\
0.0000 \\
0.0000 \\
0.0000\end{array}$ & $\begin{array}{r}-32.1129 \\
0.0000 \\
0.0000 \\
0.0000 \\
0.0000 \\
0.0000 \\
0.0000 \\
0.0000\end{array}$ & $\begin{array}{r}0.0000 \\
0.0000 \\
-0.0148 \\
1.0000 \\
0.0000 \\
-10.0000 \\
0.0000 \\
0.0000\end{array}$ & $\begin{array}{r}0.0000 \\
0.9909 \\
0.0000 \\
0.0000 \\
1.0000 \\
0.0000 \\
-.0000 \\
0.0000\end{array}$ & $\left.\begin{array}{r}0.0000 \\
0.0000 \\
-0.9919 \\
-0.0133 \\
0.0000 \\
0.0000 \\
0.0000 \\
-2.0000\end{array}\right]$ \\
\hline$B_{m}=$ & {$\left[\begin{array}{r}-2.2032 \\
-0.0848 \\
-0.0166 \\
0.0000 \\
0.0000 \\
11.2379 \\
-7.8229 \\
0.0000\end{array}\right.$} & $\begin{array}{r}-2.2032 \\
-0.0848 \\
0.0166 \\
0.0000 \\
0.0000 \\
-11.2379 \\
-7.8229 \\
0.0000\end{array}$ & $\begin{array}{r}-0.8354 \\
-0.0494 \\
0.0000 \\
0.0000 \\
0.0000 \\
29.0513 \\
0.0000 \\
0.0000\end{array}$ & $\begin{array}{r}-0.8354 \\
-0.0494 \\
0.0000 \\
0.0000 \\
0.0000 \\
-29.0513 \\
0.0000 \\
0.0000\end{array}$ & $\left.\begin{array}{r}0.0000 \\
0.0000 \\
0.0647 \\
0.0000 \\
0.0000 \\
9.6847 \\
0.0000 \\
-6.6502\end{array}\right]$ & & & \\
\hline
\end{tabular}


TABLE 2. - EIGENSYSTEM ASSIGNMENT AND GAINS

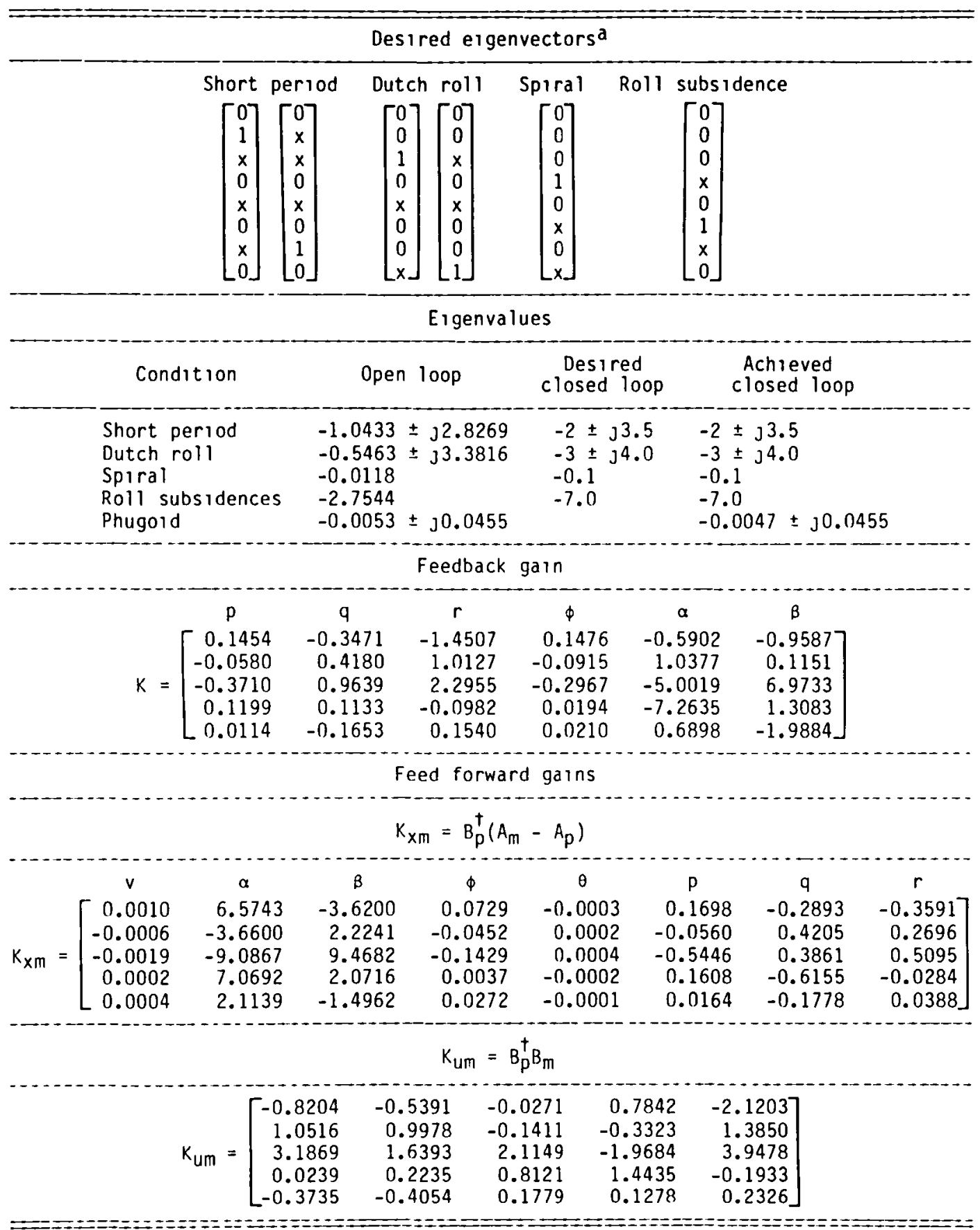

${ }^{a} x$ is arbitrary.

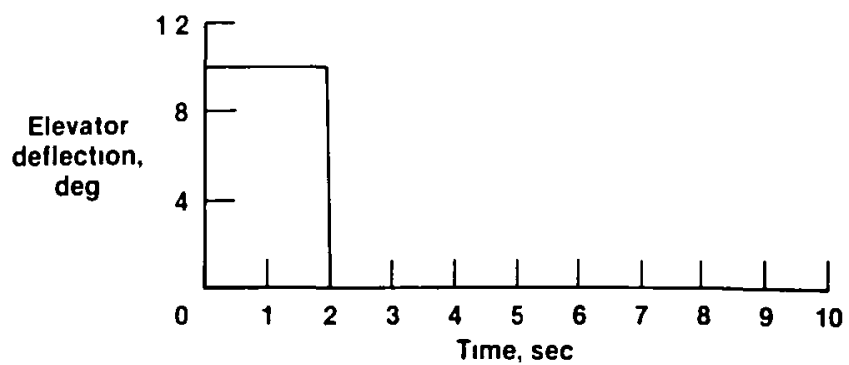

Fig. 1 Command input to system. 


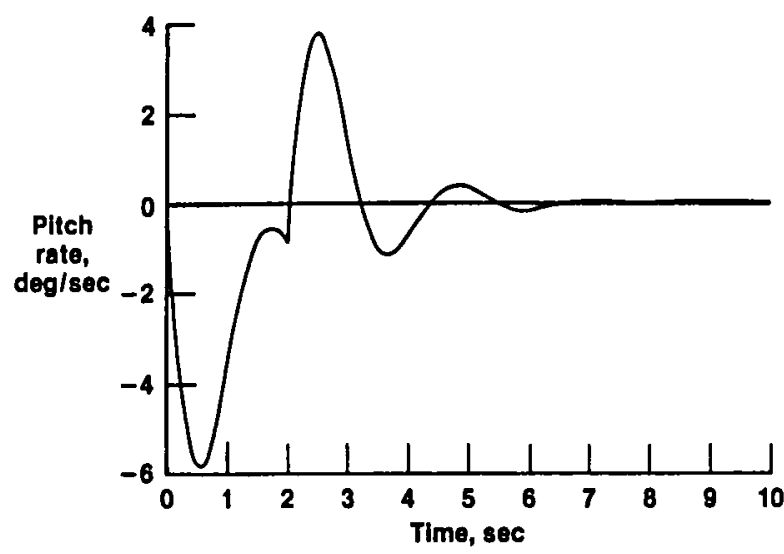

(a) Pitch rate.

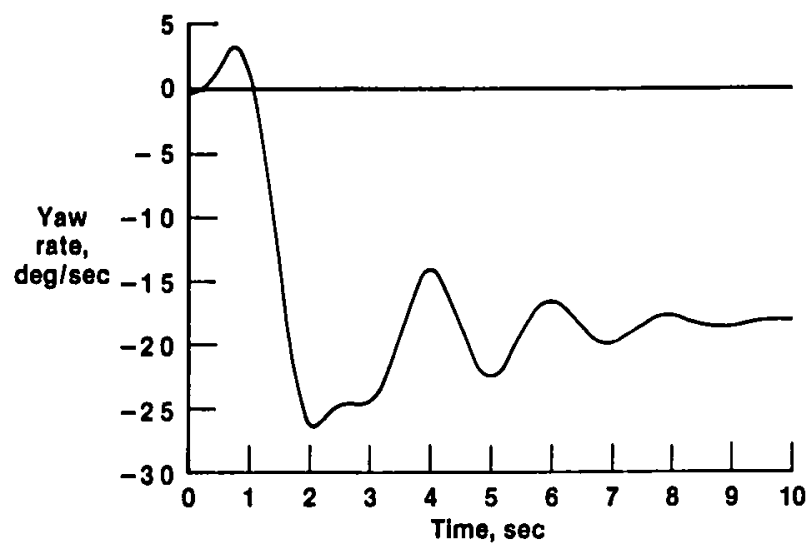

(b) Yow rate.

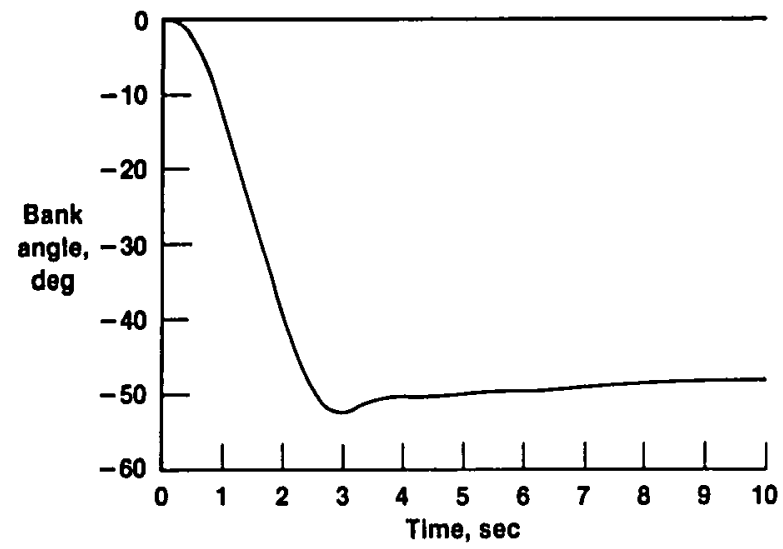

(a) Bank angle.

Fig. 2 Open-loop system response to elevator comand input.

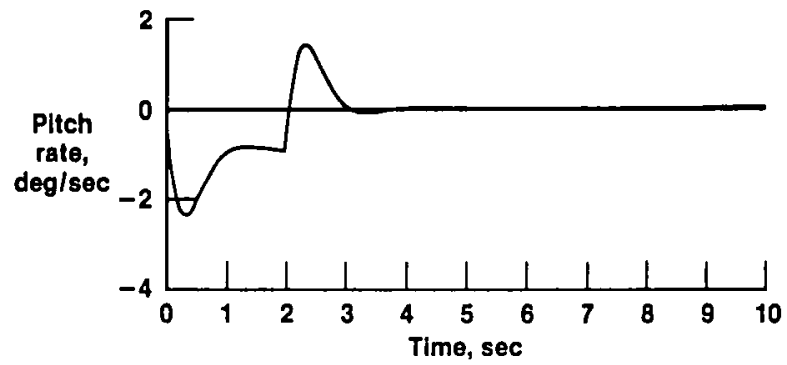

(a) Pitoh rate.

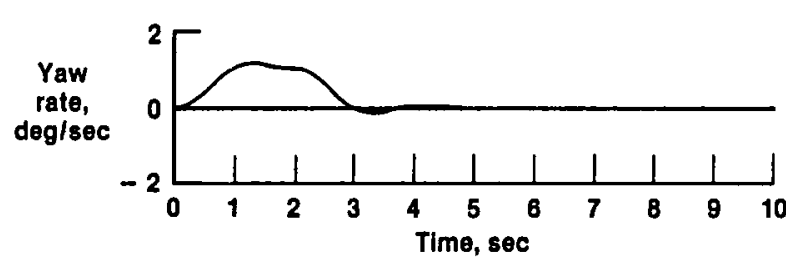

(b) Yow rate.

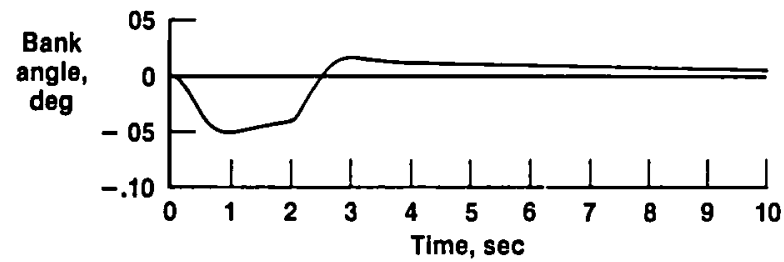

(c) Bank angle.

Fig. 3 Closed-loop system response to elevator command input. 


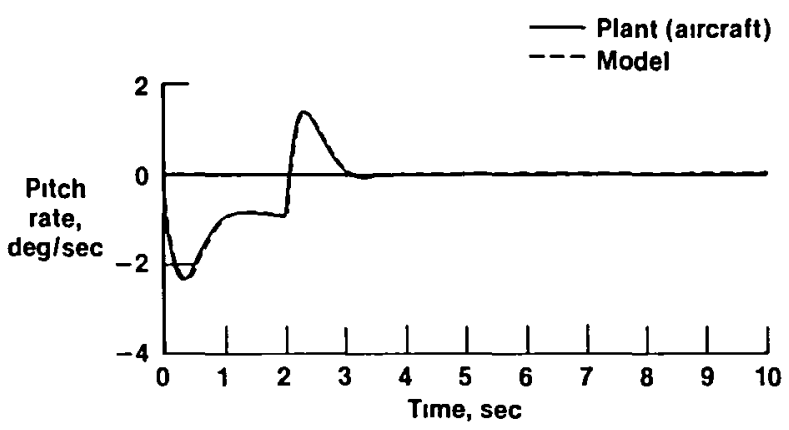

Fig. 4 Model-following response to elevator command input.

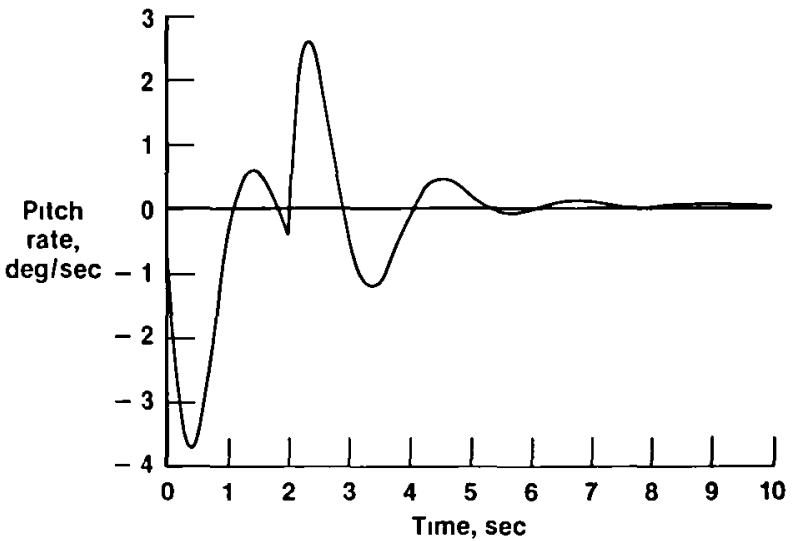

(a) Pitch rate.

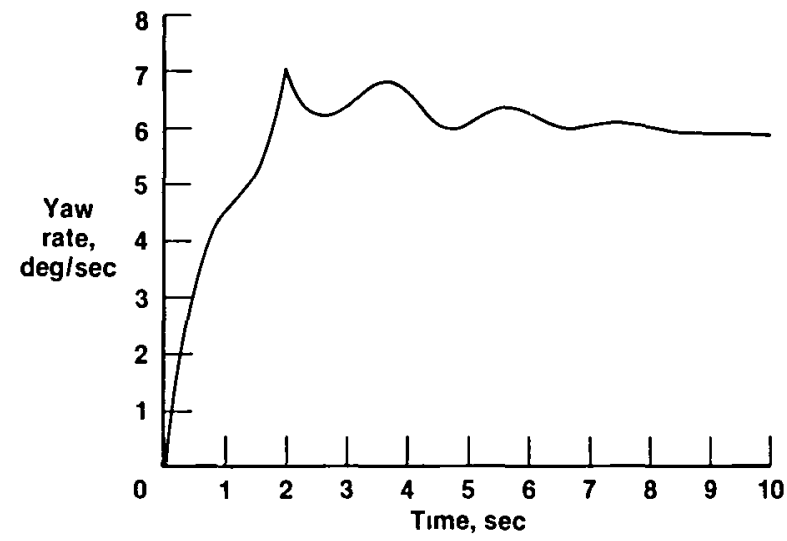

(b) Yaw rate.

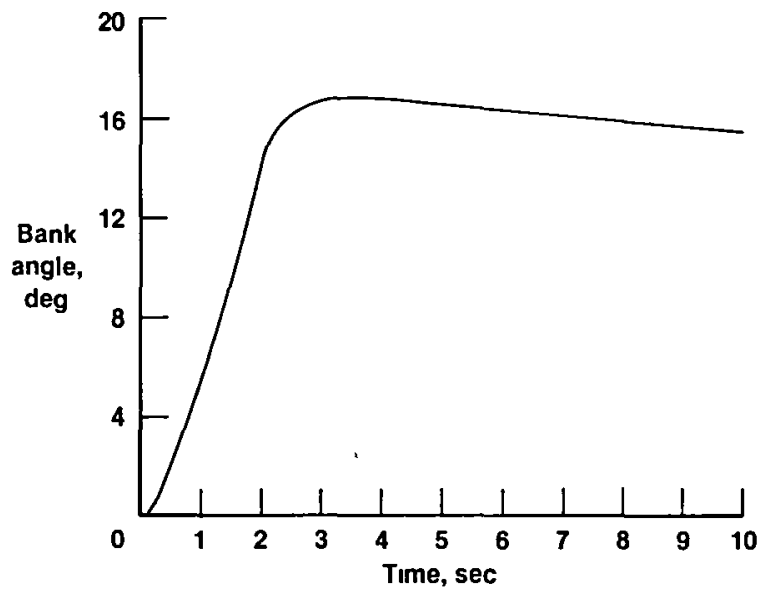

(c) Bank angle.

Fig. 5 Open-loop system response to aileron command input. 


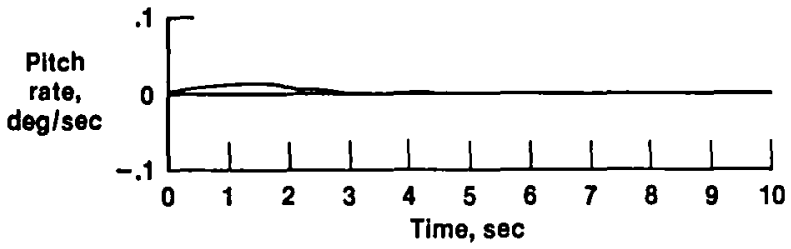

(a) Pitch rate.

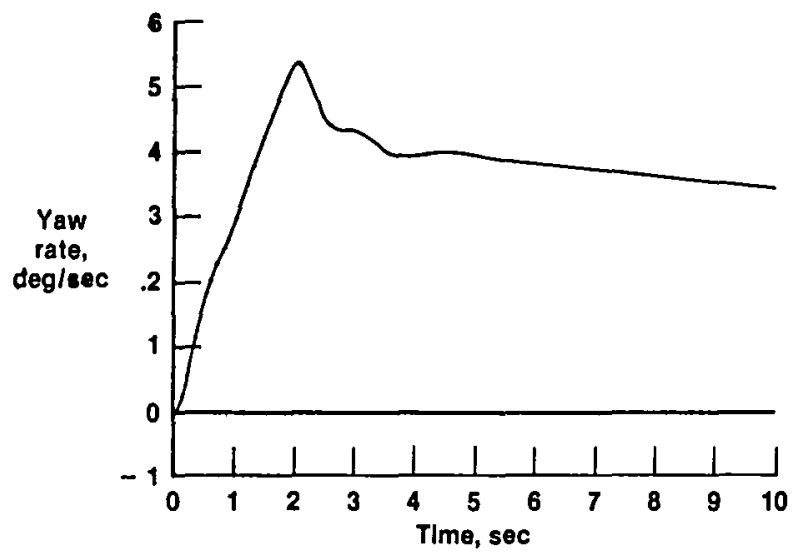

(b) Yow rate.

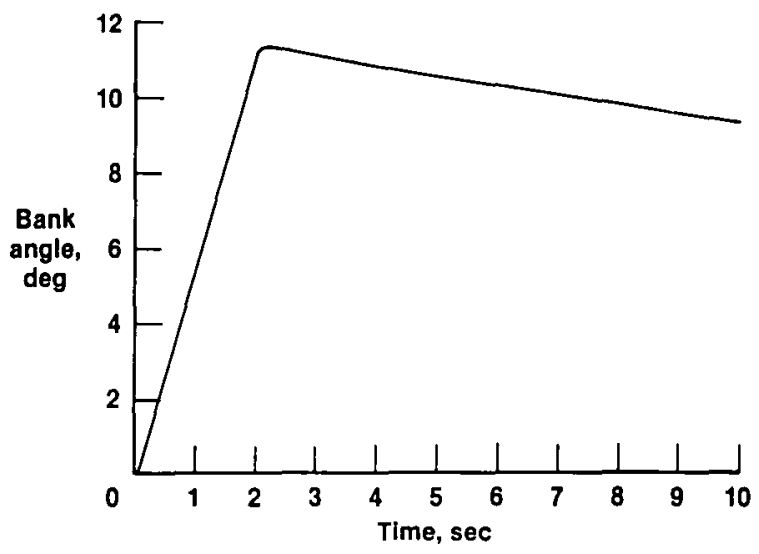

(c) Bank angle.

Fig. 6 Closed-loop system response to aileron comand input.

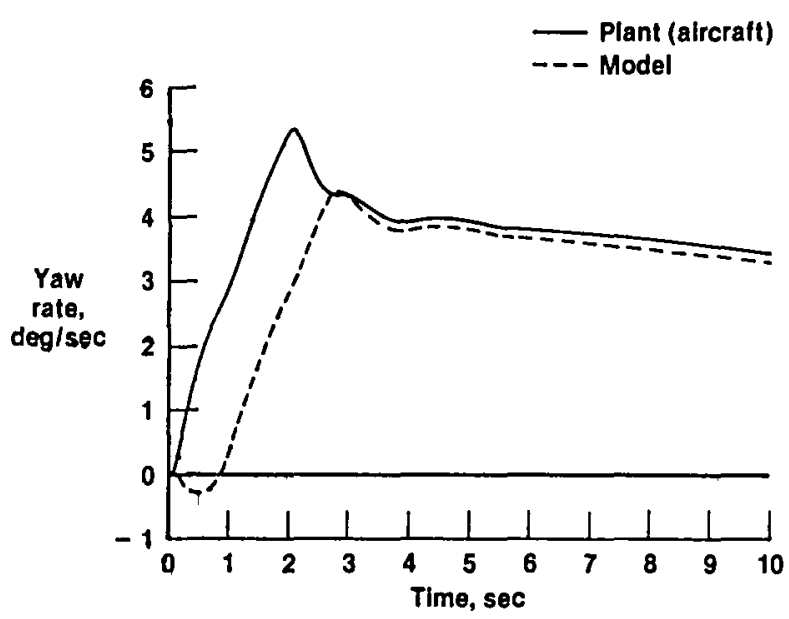

(a) Yaw rate.

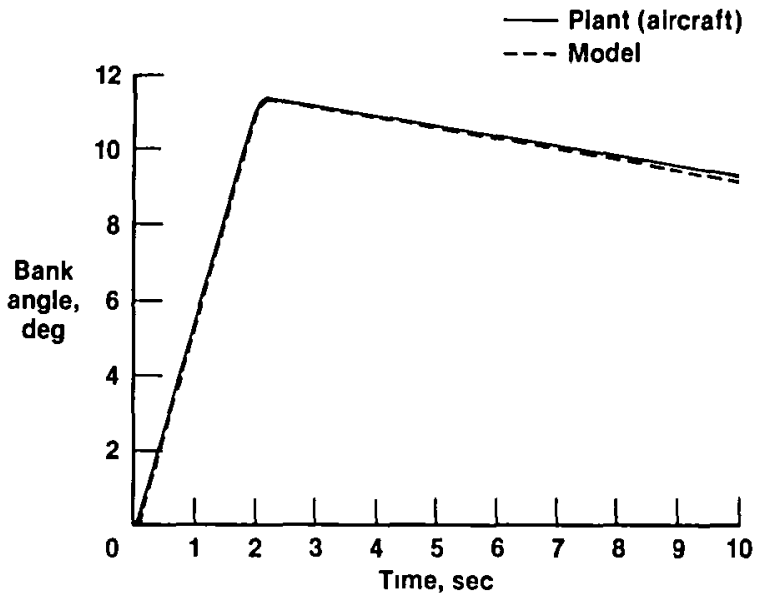

(b) Bank angle.

Fig. 7 Model-following response to aileron comnand input. 


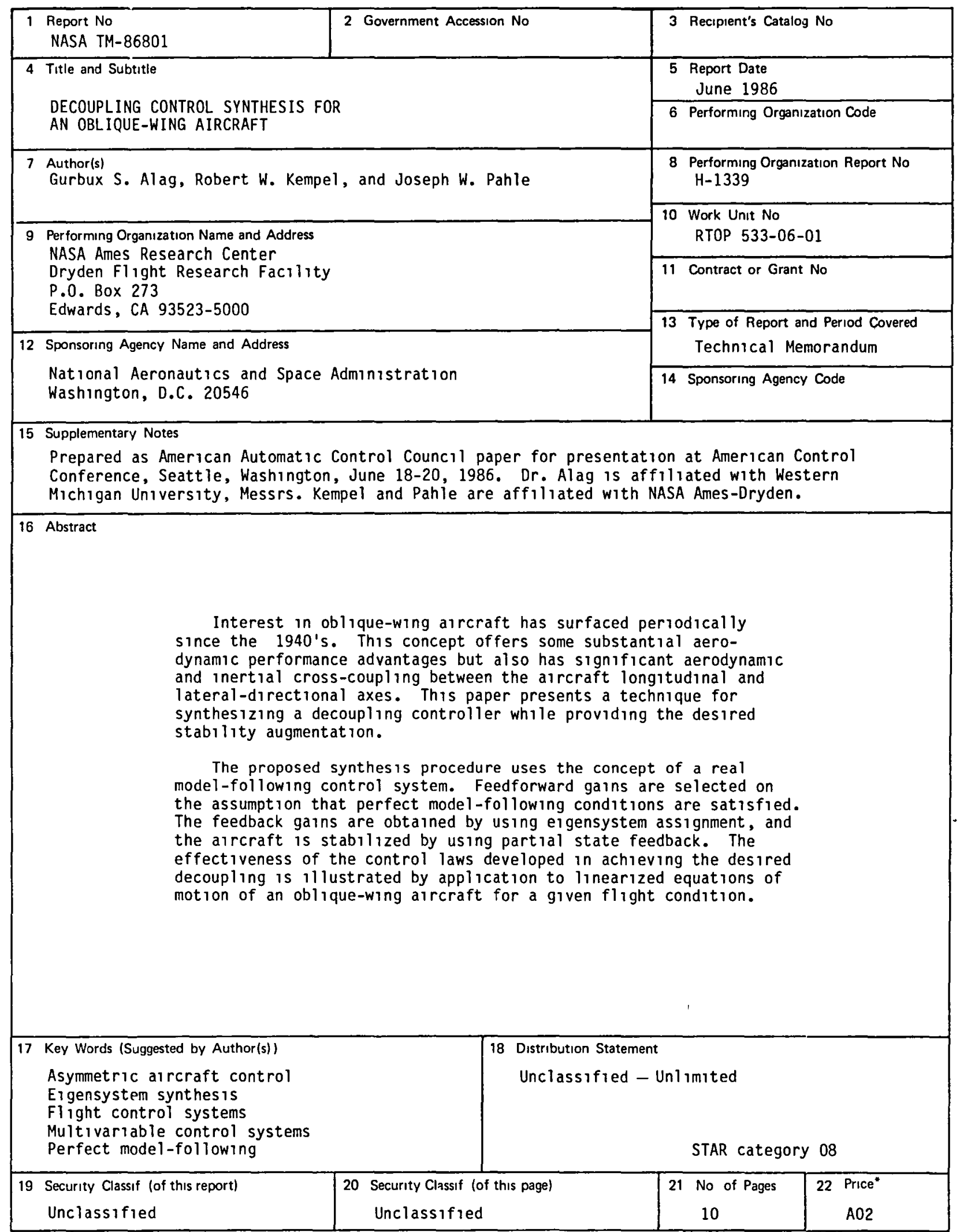

*For sale by the National Technical Information Service, Springfield, Virgrnia 22161. 


\section{End of Document}

